\title{
Aggregation behavior of Triton X-114 and Tween 80 at various temperatures and concentrations studied by density and viscosity measurements
}

\author{
Katarzyna Szymczyk ${ }^{1}$ - Anna Taraba ${ }^{1}$
}

Received: 9 November 2015/Accepted: 12 June 2016/Published online: 5 July 2016

(c) The Author(s) 2016. This article is published with open access at Springerlink.com

\begin{abstract}
Measurements of density and viscosity for the aqueous solutions of the nonionic surfactants, Triton X-114 and Tween 80 , have been taken in the temperature range $T=293-318 \mathrm{~K}$ at an interval of $5 \mathrm{~K}$. On the basis of the obtained results, various parameters have been calculated and analyzed including concentration of surfactants in the bulk phase and temperature, for example volume expansivity and fractional free volume, which indicates that water around the Tween 80 molecules is more loosely bound than the Triton X-114. Moreover, it was proved that depending on the temperature and concentration of studied surfactants they can behave as a water structure breaker or maker.
\end{abstract}

Keywords Triton X-114 · Tween 80 - Density · Viscosity · Volume expansivity $\cdot$ Enthalpy of activation

\section{Introduction}

Separation methods based on cloud point extraction (CPE) are practical application of surfactants in analytical chemistry and have become an alternative to solvent extraction. Compared with the conventional solvent extraction, CPE uses surfactants and avoids utilizing a large amount of expensive, toxic and flammable organic solvents [1]. In the CPE process, nonionic surfactants are used as an extractant, under suitable conditions (surfactant

Katarzyna Szymczyk

katarzyna.szymczyk@poczta.umcs.lublin.pl

1 Department of Interfacial Phenomena, Faculty of Chemistry, Maria Curie-Skłodowska University, Maria CurieSkłodowska Sq. 3, 20-031 Lublin, Poland concentration, salt additive, temperature and time), the extraction occurs at a cloud point temperature where the surfactant becomes cloudy (at a higher temperature than its critical temperature) resulting in two-phase separation involving the surfactant-rich phase (SRP) and the aqueous phase (AQ) [2-4].

The nonionic surfactant Triton X-114 (TX114) is widely used for CPE [5-8], and since Bordier [9] introduced it for enrichment of membrane proteins, this application has been useful in many studies. This is because of low cloud point temperature of TX114 and high density of the surfactant-rich phase as well as its low commercial cost and lower toxicity. On the other hand, nonionic surfactants belonging to the Tween series are known for their assistance in separating such pollutants such as hydrophobic organic compounds from water and soils $[10,11]$. Tweens are clear, non-odorous, readily pourable liquids at room temperature. Their low toxicity and acceptable degree of biodegradability are responsible for their extensive utility. In addition, some authors claim that Tween 80 surfactant exhibits lyotropic liquid crystal properties at certain concentrations and temperature, when dissolved in appropriate solvents [12, 13]. However, not sufficient information is available in the literature on the changes in the properties of aqueous solutions of Tween 80 with the temperature related to the macro-level and the mechanism of interactions present in such system. Therefore, for a better understanding of these properties densities and viscosities of aqueous solutions of Tween 80 as well as TX114 have been measured. The temperature of the experiment ranges from $T=293-318 \mathrm{~K}$ at an interval of $5 \mathrm{~K}$. Furthermore, various molecular interactions in these solutions have been analyzed on the basis of alteration of these parameters with concentration and temperature. 


\section{Experimental}

Triton X-114 (TX114) and Tween 80 (purity greater than $99 \%$ ) were purchased from Sigma-Aldrich and used without further purification. The aqueous solutions of the mentioned surfactants were prepared in the concentration range from $10^{-6}$ to $10^{-2} \mathrm{M}$ using doubly distilled and deionized water obtained from a Destamat Bi18E distiller.

The density of the aqueous solution of studied surfactants was measured with a U-tube densitometer (DMA 5000 Anton Paar) in the temperature range 293-318 K. The precision of the density and temperature measurements given by the manufacturer is $\pm 0.000005 \mathrm{~g} \mathrm{~cm}^{-3}$ and $\pm 0.001 \mathrm{~K}$. The uncertainty was calculated to be equal to $0.01 \%$. The densitometer was calibrated regularly with distilled and deionized water.

All viscosity measurements of the aqueous solutions of the studied surfactants were performed with the Anton Paar viscometer (AMVn) at $293-318 \mathrm{~K} \pm 0.01 \mathrm{~K}$ with the precision of $0.0001 \mathrm{mPa} s$ and the uncertainty $0.3 \%$.

\section{Results and discussion}

The increase in $T$ of the sample liquid results in the volume expansion causing more spacing between the molecules of the surfactant leading to a less ordered structure due to the decrease in the cohesive force between the molecules of the samples [14]. For this reason, the density $(\rho)$ of aqueous solutions of the studied surfactants, Triton X-114 (TX114) and Tween 80, decreases with the rise in $T$ (Fig. 1 as an example). This decreasing $\rho$ is consistent with the increasing tendency of the partial molar volume $\left(V_{\mathrm{M}}\right)$ of solutions (Fig. 2) at concentrations higher than the critical micelle concentration (CMC) of studied surfactants determined at $293 \mathrm{~K}$ from the surface tension measurements (e.g., $1.68 \times 10^{-4} \mathrm{M}$ for TX114 and $2.7 \times 10^{-5} \mathrm{M}$, $1.6 \times 10^{-5} \mathrm{M}$ for Tween 80) [15-17]. So, loosening of the molecular packing in the liquid with the rise of temperature should be responsible for all structural changes. Apparent molar volume, $\varphi_{\mathrm{V}}$, is also a useful property for studying structure interactions and micelle formation in surfactant solution. This parameter provides an idea about the structure making or breaking role of the solute component in the solution and is a sensitive function of solute-solvent and solute-cosolute interactions [18]. The dependency of $\varphi_{\mathrm{V}}$ values on temperature and concentration of TX114 and Tween 80 higher than their CMC is evident from Figs. 3 and 4 (as an example). The increase in $\varphi_{\mathrm{V}}$ values is observed with the increasing concentration of the studied surfactants $(C)$ for a given temperature which suggests that the solute (surfactant)-solvent interactions become stronger with the $C$ increase [18]. However, these interactions should be different for TX114 and Tween 80 because both the hydrophobic and hydrophilic parts of TX114 molecules are smaller than the corresponding parts in Tween 80 (at $T=293 \mathrm{~K}$ and $C=10^{-2} \mathrm{M} \varphi_{\mathrm{V}}=514.43$ and $1129.33 \times$ $10^{6} \mathrm{~m}^{3} \mathrm{~mol}^{-1}$ for TX114 and Tween 80 , respectively). While the hydrophobic parts of Tween 80 are all aliphatic, this part of TX114 has an aromatic ring in the chain $[19,20]$. In addition, it is known that the oxyethylene group (EO), from which the hydrophilic part of surfactants is
Fig. 1 A plot of the values of density $(\rho)$ of aqueous solutions of TX114 (curve 1) and Tween 80 (curve 2) at $T=293 \mathrm{~K}$ versus the logarithm of the concentration of surfactant, $C$, as well as the values of $\rho$ of aqueous solutions of TX114 and Tween 80 at $C=10^{-4}, 10^{-3}$ and $10^{-2} \mathrm{M}$ versus the temperature, $T$

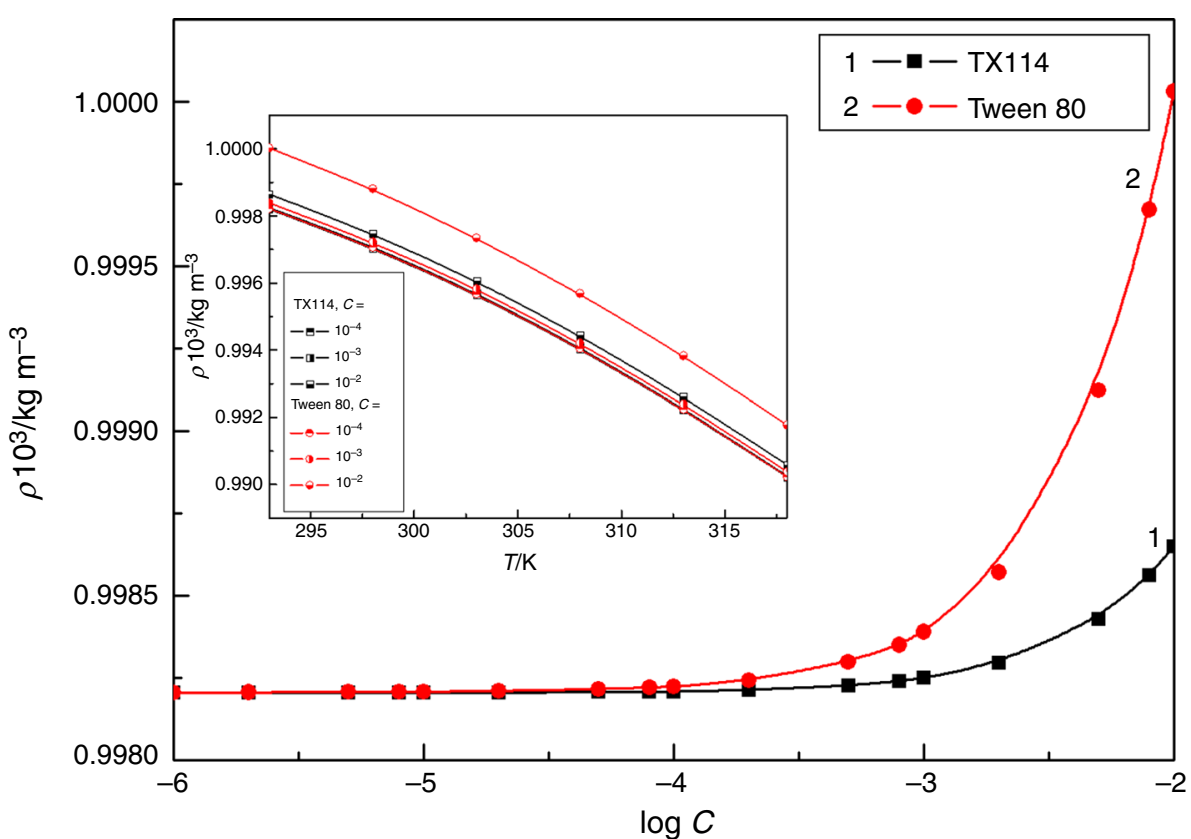



the partial molar volume $\left(V_{\mathrm{M}}\right)$ of aqueous solutions of TX114 (curve 1) and Tween 80 (curve 2) versus the temperature, $T$
Fig. 2 A plot of the values of

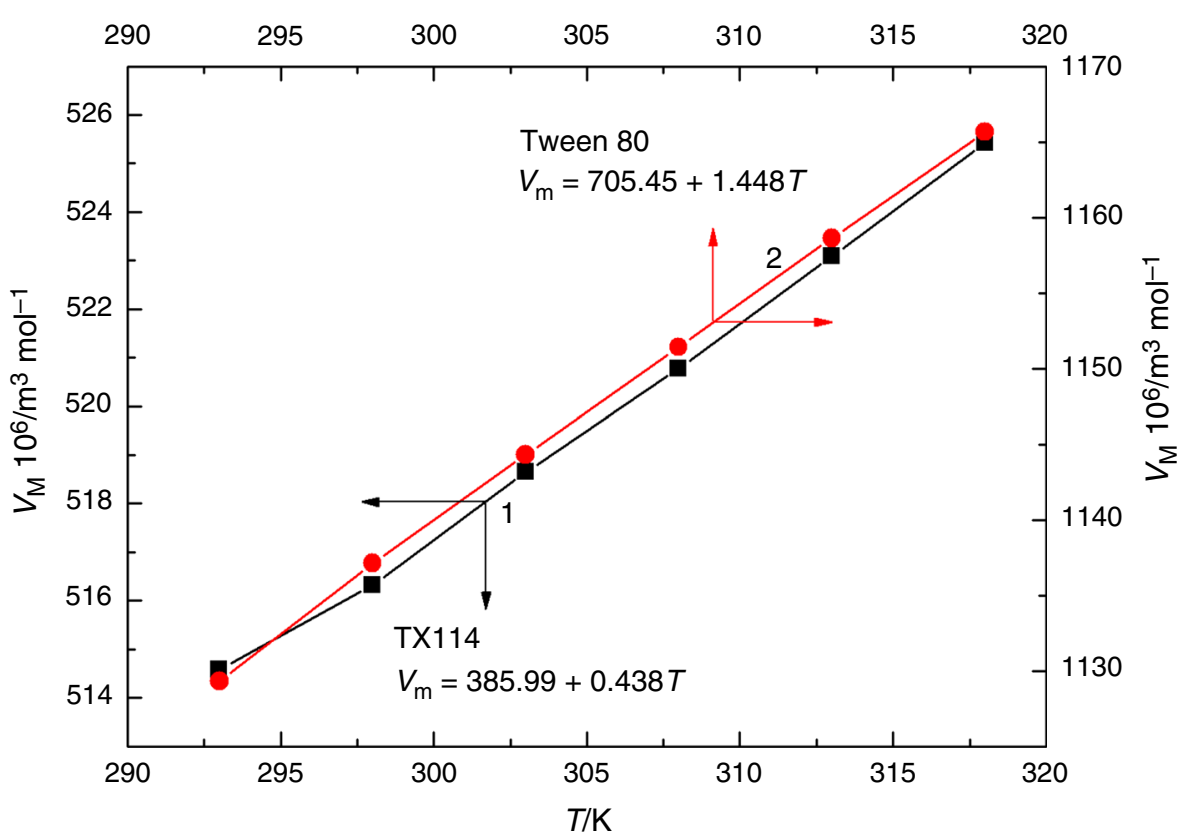

Fig. 3 A plot of the values of apparent molar volume, $\varphi_{\mathrm{V}}$, of aqueous solutions of TX114 at $C=2 \times 10^{-3}$ (curve 1$)$ $5 \times 10^{-3}$ (curve 2$), 8 \times 10^{-3}$ (curve 3 ) and $10^{-2} \mathrm{M}$ (curve 4$)$ versus the temperature, $T$, as well as the values of $\varphi_{\mathrm{V}}$ of aqueous solutions of TX114 at $T=293 \mathrm{~K}$ versus the logarithm of the concentration of TX114, $C$

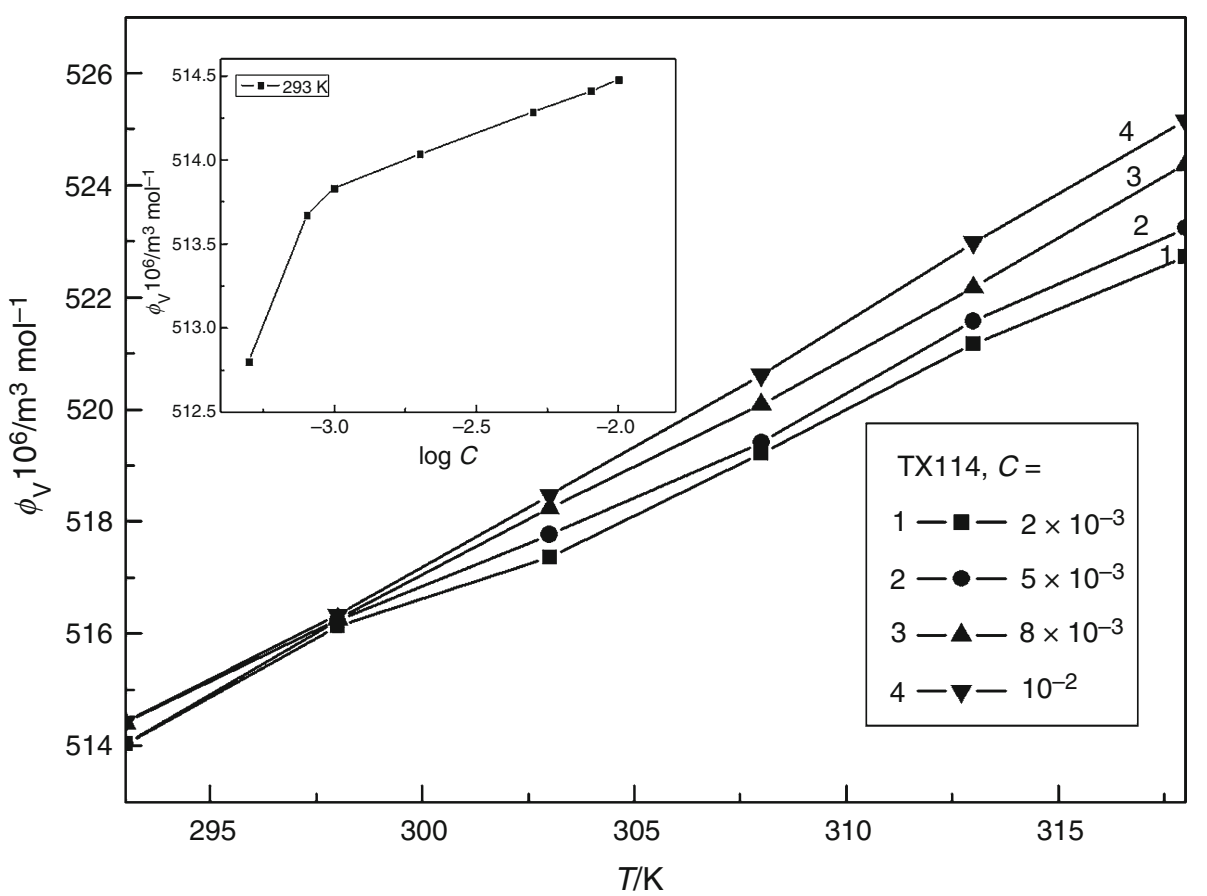

built, can be associated with two molecules of water [21] or that most of water molecules are mechanically trapped in the polyoxyethylene chains of nonionic surfactants, with 5.2-10.5 water molecules per oxyethylene units [22, 23]. It is also noted that different water species of varying strength and coordination participate in hydration of the EO groups. A gradual change in the hydration of the oxyethylene groups along the chain is also observed [24, 25]. A significant portion of water molecules present in the headgroup region with preferred orientation was found to be forming weak hydrogen bonds in a liquid-like state [24]. Of course, the interactions of EO groups with water can be different for surfactant in the monomeric form and in the micelle. In the literature, it is possible to find that the oxyethylene units are not only restricted to the polar phase but some of them are extended into the hydrocarbon phase of the micelle [22] and can penetrate its hydrophobic core [23]. It was also previously reported that in the nonionic 
Fig. 4 A plot of the values of apparent molar volume, $\varphi_{\mathrm{V}}$, of aqueous solutions of Tween 80 at $C=2 \times 10^{-3}$ (curve 1 ), $5 \times 10^{-3}$ (curve 2 ), $8 \times 10^{-3}$ (curve 3 ) and $10^{-2} \mathrm{M}$ (curve 4 ) versus the temperature, $T$, as well as the values of $\varphi_{\mathrm{V}}$ of aqueous solutions of Tween 80 at $T=293 \mathrm{~K}$ versus the logarithm of the concentration of Tween $80, C$

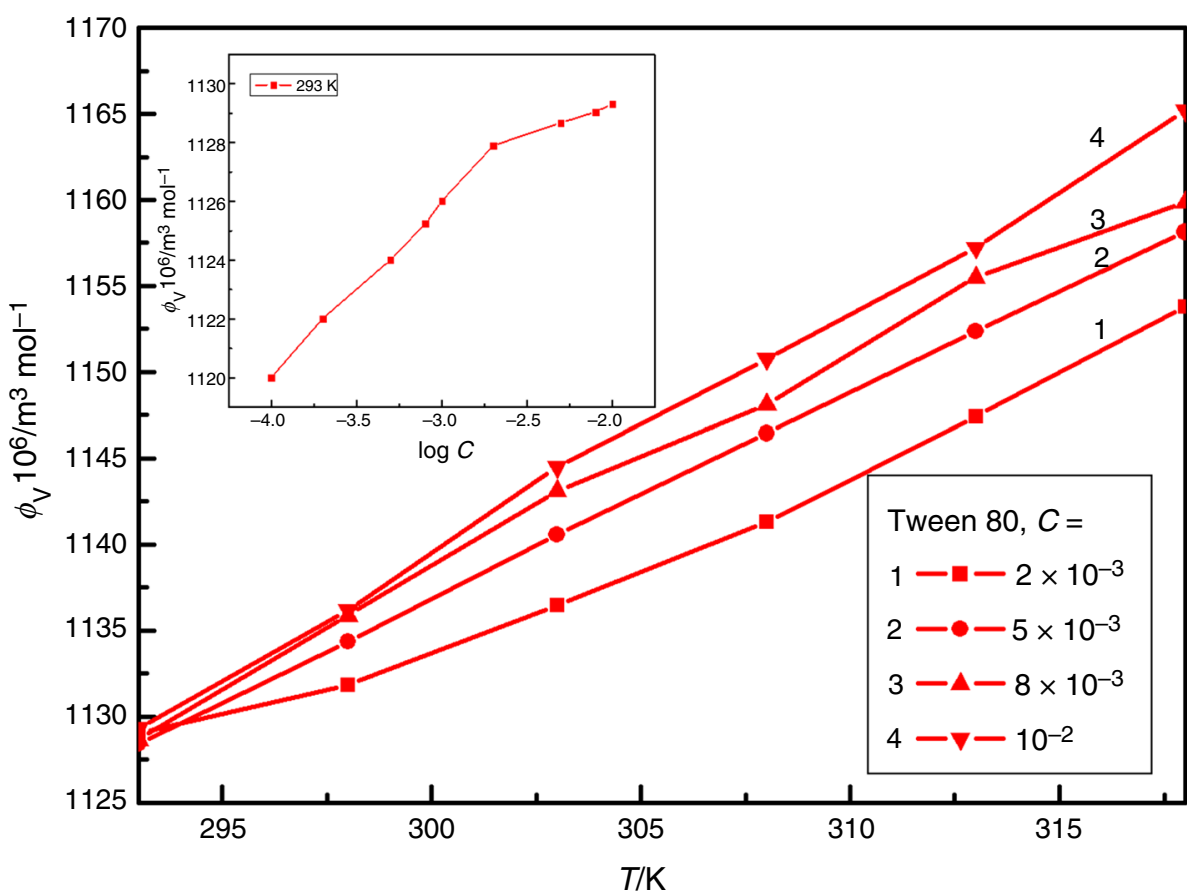

surfactants consisting of POE groups, the oxonium ions are formed in the hydrophilic portion of the surfactants [26]. However, the number of ions formed is very small [22]. On the other hand, Robson claimed that above the CMC the micelles of surfactants like TX114 consist of a tightly packed deep core of hydrocarbon and a hydrated POE shell occupying the major part of the micelle volume (around $83 \%$ of the total volume) [27].

From Figs. 3 and 4 for the studied surfactants at $C$ higher than $10^{-3} \mathrm{M}$, there is almost a linear increase in $\varphi_{\mathrm{V}}$ values with $T$, which suggests significant structural changes in the studied surfactant micelles with the increasing temperature and/or changes in the intermolecular interactions occurring between surfactants and water. These interactions can be described, among others, from the values of the volume expansivity, $\alpha$, also known as the coefficient of thermal expansion, which is a measure how the volume changes with the temperature [18, 28]. For both surfactants, the calculated values of $\alpha$ increase with the rise in $T$, but the relationship between $\alpha$ and $\log C$ for a given surfactant and temperature is more interesting (Fig. 5 as an example). On the $\alpha=f(\log C)$ curves for TX114 and Tween 80 at $T=293 \mathrm{~K}$, there are two break points-the first corresponds to the values of CMC determined from the surface tension measurements and the second is close to $C=10^{-3} \mathrm{M}$. This suggests the existence of the second value of CMC of TX114 and Tween 80 in which the micelle structure changes and/or admicelles are changed into micelles [28]. It is known that amphiphilic molecules generally form spherical aggregates in aqueous solutions above the CMC, but, under certain conditions these spherical micelles grow in size or change their shape resulting in the formation of rodlike structures or even long flexible micelles [29-33]. It is interesting that for both surfactants at $T=293 \mathrm{~K}$, the values of $\alpha$ decrease up to that of the first $\mathrm{CMC}$, then they are almost constant at $C$ between the first and second CMC and next grow up, especially for Tween 80. Greater values of volume expansivity for Tween 80 than for TX114 at the concentrations higher than $10^{-4} \mathrm{M}$ suggest that the water around Tween 80 is loosely bound.

Knowing the values of $\alpha$, it is possible to calculate the thermodynamic parameters such as the Sharma parameter, $S_{0}$, and the fractional free volume, $f[34,35]$. The $S_{0}$ relates the isothermal volume derivative of intermolecular constant to the thermodynamic Gruneisen parameter. It is an important parameter for investigating the physicochemical behavior of any system which, in turn, will help understand molecular order and intermolecular interactions in the condensed phase [35]. As for the reports of Sharma and Sharma and Reddy [36, 37], the value of the Sharma constant is the one for any system, in either a liquid or solid state. From their investigations, Sivaram and Venkatacharyulu [38] and Subba Rao [39] concluded that the Sharma constant $S_{0}$ is equal to $1.11 \pm 0.01$. On the other hand, based on their studies they observed that in some cases $S_{0}$ assumes a lower value than the characteristic one. This situation is found only in the close vicinity of transition temperatures when the system transits from an isotropic liquid state to a mesomorphic state (nematic or smectic), i.e., from a completely disordered low-density 
Fig. 5 A plot of the volume expansivity, $\alpha$, of aqueous solutions of TX114 (curve 1) and Tween 80 (curve 2) at $T=293 \mathrm{~K}$ versus the logarithm of the concentration of surfactant, $C$, as well as the values of $\alpha$ of aqueous solutions of TX114 and Tween 80 at $C=10^{-4}, 10^{-3}$ and $10^{-2} \mathrm{M}$ versus the temperature, $T$

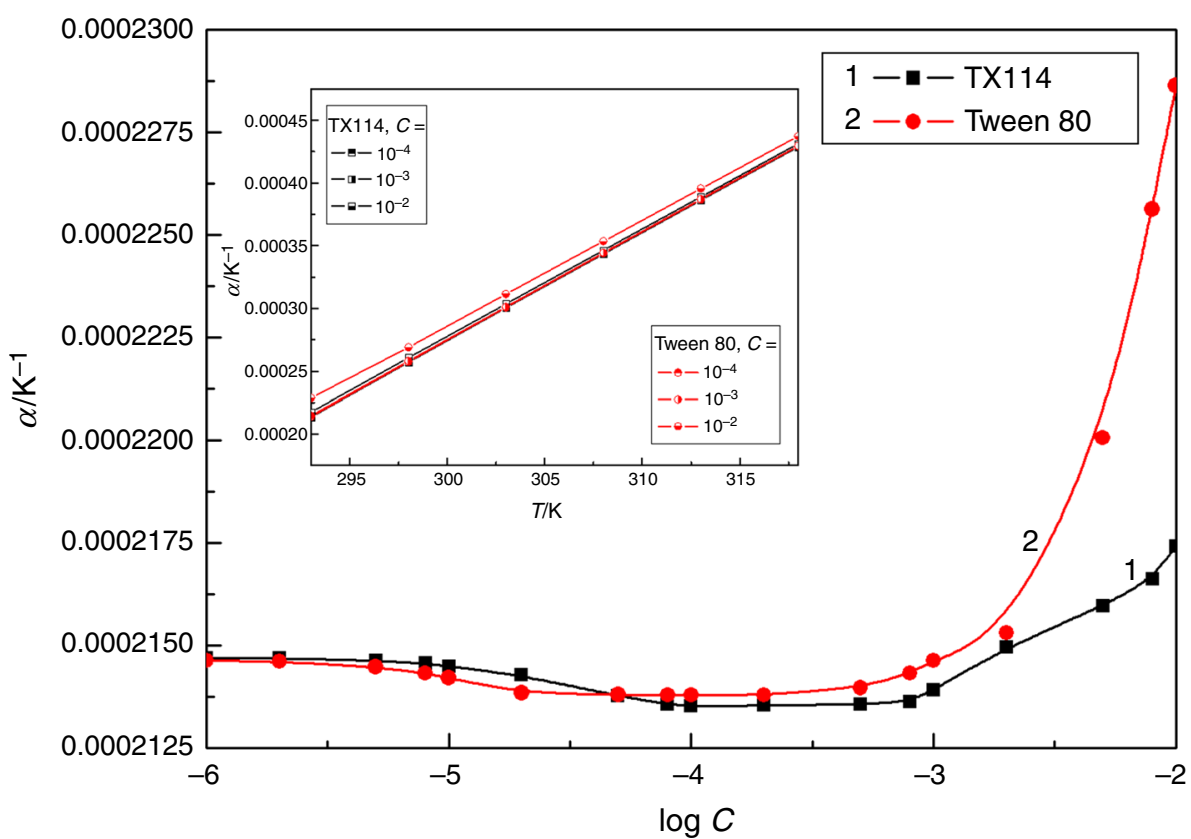

isotropic liquid state to a more-ordered (orientationally or positionally) density state. Just at the transition temperature, $S_{0}$ drops to the lower value than at any other temperature. From the performed calculations, it results that for the aqueous solutions of studied surfactants, the values of Sharma parameter change significantly with the surfactant concentration and temperature (Fig. 6 as an example). Also all values of $S_{0}$ are smaller than 1.11. It follows from Fig. 7 that the values of fractional free volume, $f$, which determine disorder due to the molecules mobility, also significantly change with the concentrations of studied surfactants (curves 1 and 2 for $293 \mathrm{~K}$ as an example) and temperature. As the temperature increases the values of the fractional free volume, $f$, also increase, but the highest values of $f$ are observed for Tween 80 at the concentrations higher than $10^{-3} \mathrm{M}$ and $T=318 \mathrm{~K}$, which confirms that water molecules are loosely bound around the molecules of this surfactant.

In fact, such situation should be also reflected in the changes in viscosity of studied solutions. The dynamic
Fig. 6 A plot of the Sharma parameter, $S_{0}$, of aqueous solutions of TX114 (curve 1) and Tween 80 (curve 2) at $T=293 \mathrm{~K}$ versus the logarithm of the concentration of surfactant, $C$, as well as the values of $S_{0}$ of aqueous solutions of TX114 and Tween 80 at $C=10^{-4}, 10^{-3}$ and $10^{-2} \mathrm{M}$ versus the temperature, $T$

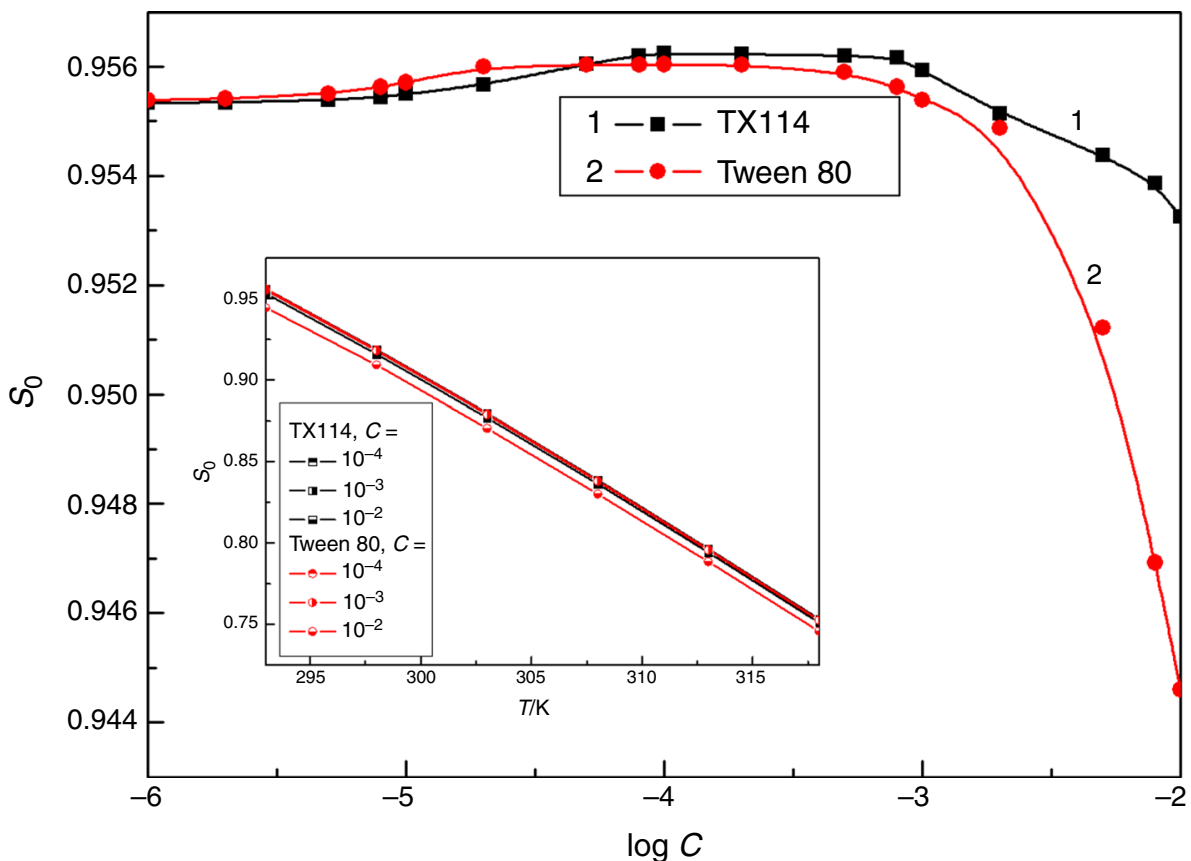


Fig. 7 A plot of the fractional free volume, $f$, of aqueous solutions of TX114 (curve 1) and Tween 80 (curve 2) at $T=293 \mathrm{~K}$ versus the logarithm of the concentration of surfactant, $C$, as well as the values of $f$ of aqueous solutions of TX114 and Tween 80 at $C=10^{-4}, 10^{-3}$ and $10^{-2} \mathrm{M}$ versus the temperature, $T$

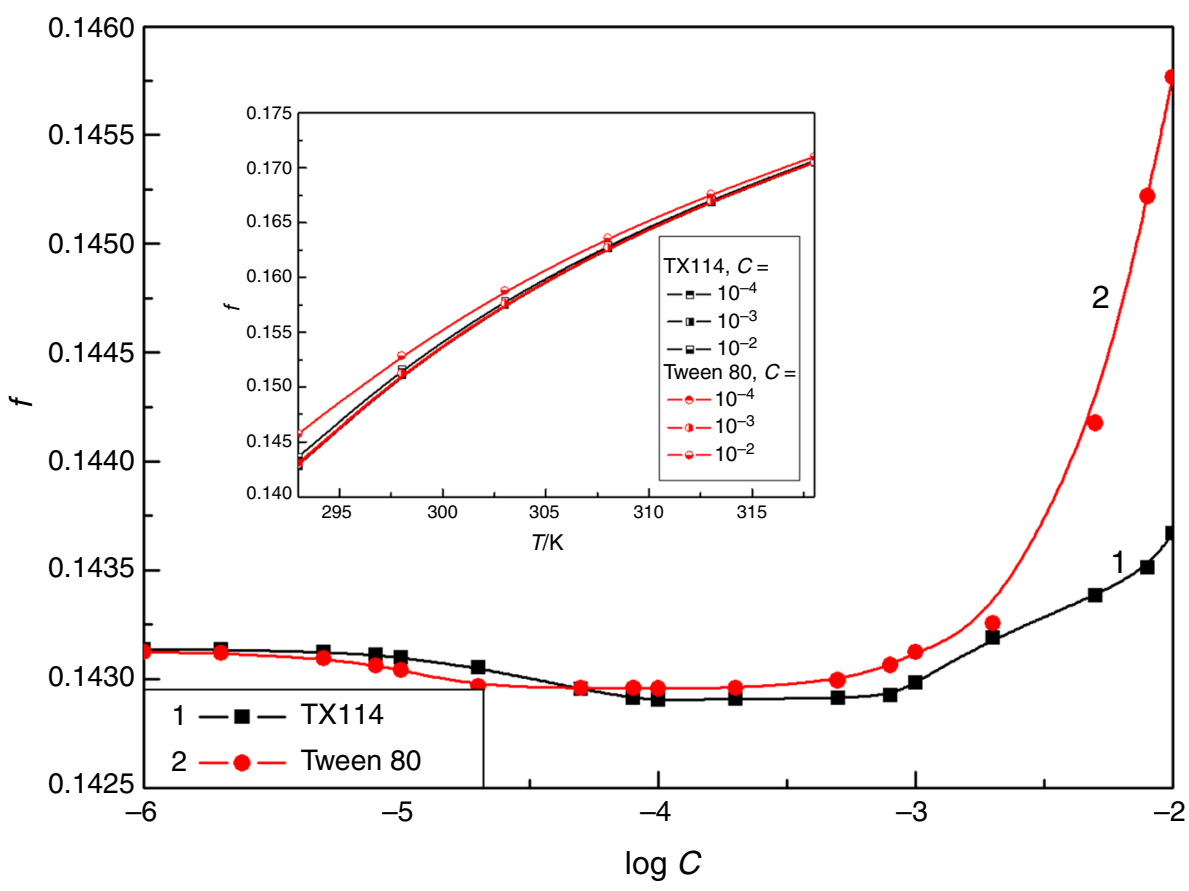

viscosity $(\eta)$ of surfactant solution is highly sensitive to temperature changes (Fig. 8 as an example). The temperature dependence of viscosity follows the Arrhenius law $[40,41]$, from which the shear activation energy $\left(E_{\mathrm{a}}\right)$ can be determined. The activation energy describes the energy that is necessary for individual micelles motion in an environment of surrounding micelles. Therefore, this parameter is given by interactions between the individual aggregates [42]. For TX114 and Tween 80, a significant change in $E_{\mathrm{a}}$ values is observed at their concentrations in the bulk phase higher than $10^{-3} \mathrm{M}$ (Fig. 9); that is, for Tween 80 these values decrease with $C$, in contrast to TX114. This confirms that above $C=10^{-3} \mathrm{M}$ water is loosely bound to Tween 80 molecules and/or its micelles. In the case of TX114, the situation is more complicated because this energy also decreases but only in the range of
Fig. 8 A plot of the values of dynamic viscosity $(\eta)$ of aqueous solutions of TX114 (curve 1) and Tween 80 (curve 2) at $T=293 \mathrm{~K}$ versus the logarithm of the concentration of surfactant, $C$, as well as the values of $\eta$ of aqueous solutions of TX114 and Tween 80 at $C=10^{-4}$, $10^{-3}$ and $10^{-2} \mathrm{M}$ versus the temperature, $T$

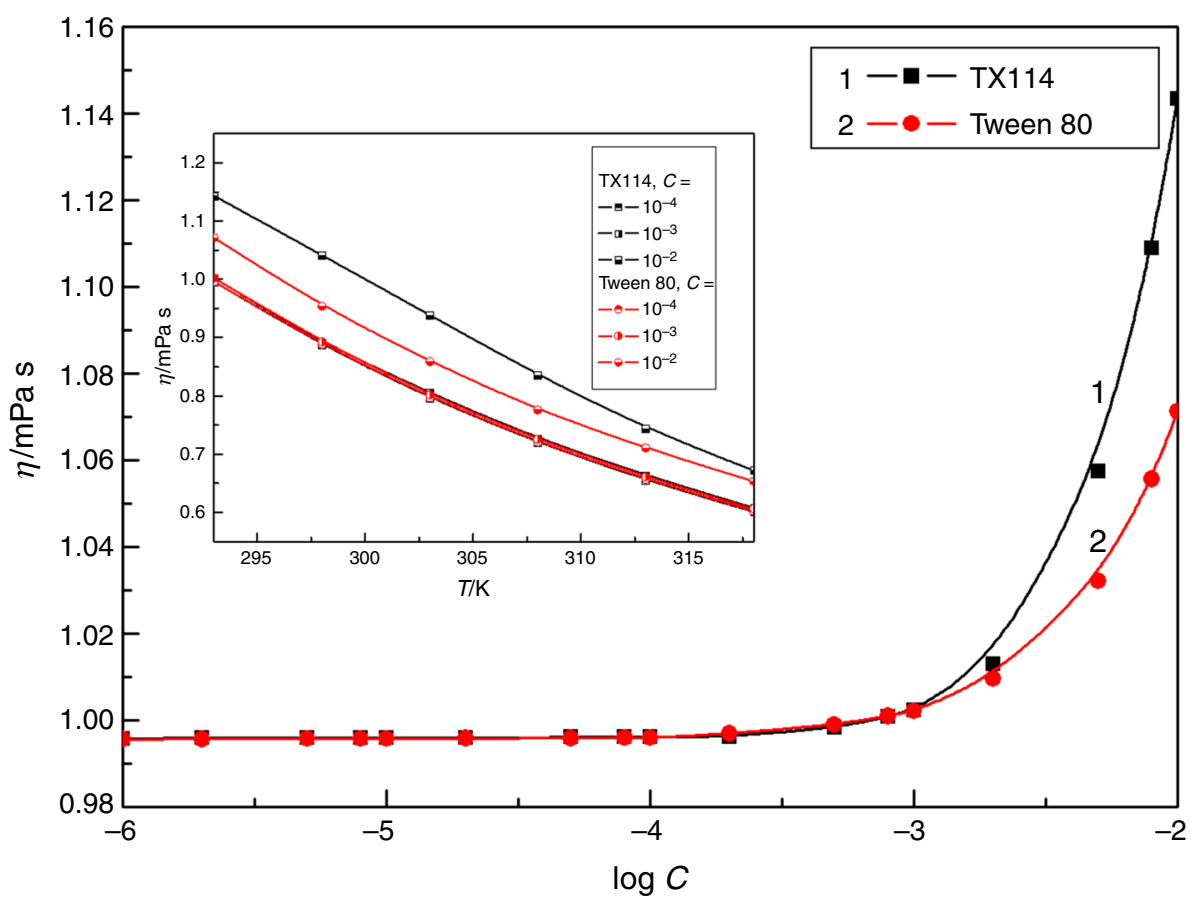


Fig. 9 A plot of the values of shear activation energy $\left(E_{\mathrm{a}}\right)$ of aqueous solutions of TX114 (curve 1) and Tween 80 (curve 2) versus the logarithm of the concentration of surfactant, $C$

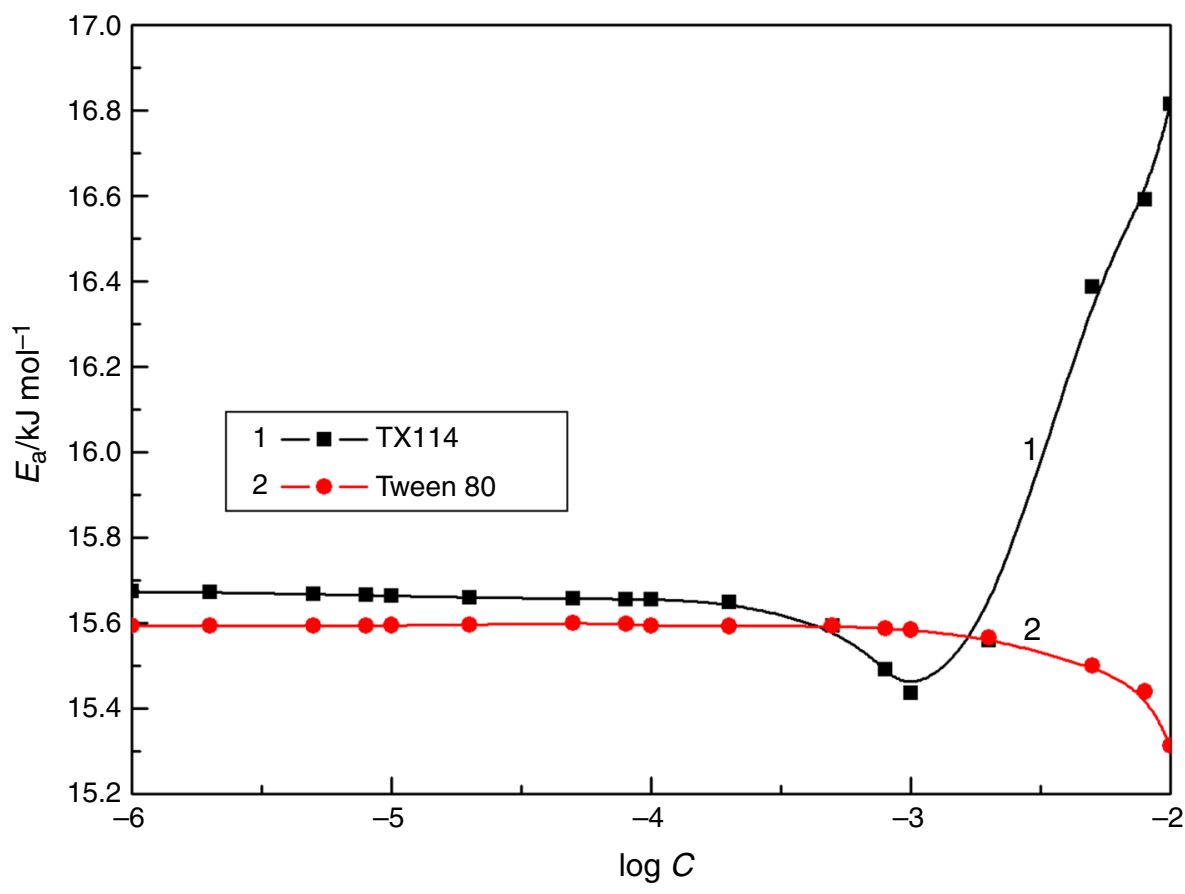

$C$ from $10^{-4}$ to $10^{-3} \mathrm{M}$. This indicates different shapes and/ or sizes of the formed micelles by TX114 and different interactions between the TX114 molecules and water.

For better explanation viscosity influence on the rate of mass transport in the studied solutions, the activation thermodynamic parameters, i.e., $\Delta H^{*}$ (enthalpy of activation) and $\Delta C_{\mathrm{p}}^{*}$ (change in heat capacity of activation), were also calculated from the relationships proposed by Mukherjee et al. [43]:

$-\frac{\Delta H^{*}}{R T^{2}}=\frac{\mathrm{d} \ln \eta}{\mathrm{d} T}$

$\Delta C_{\mathrm{p}}^{*}=\frac{\mathrm{d} \Delta H^{*}}{\mathrm{~d} T}$

It results that the calculated values of $\Delta H^{*}$ for all studied solutions are positive (Fig. 10 as an example), which means that in the studied solutions the processes are associated with the heat absorption. It is interesting that the $\Delta H^{*}$ values decline with temperature for all studied solutions, except for those of TX114 at their concentration higher than $2 \times 10^{-3} \mathrm{M}$. Also only for TX114 solutions at $C>2 \times 10^{-3} \mathrm{M}$, the values of $\Delta C_{\mathrm{p}}^{*}$ are positive and increasing linearly with $T$ (Fig. 11 as an example). For all Tween 80 solutions and TX114 at $C<2 \times 10^{-3} \mathrm{M}, \Delta C_{\mathrm{p}}^{*}$ values are negative and linearly decrease with $T$. This indicates that the structure of TX114 micelles at high concentrations and different temperatures dramatically changes.

When the amphiphiles form micelles, the hydrophobic hydration around the alkyl chain disappears and the compressibility of the aggregate becomes the dominant factor.
When the aggregate forms, the released water molecules in the vicinity of the hydrophobic part of the molecule become bulk water. The water molecules around the hydrophobic part are highly structured, having a rather low compressibility compared with the bulk water. If the amphiphile becomes longer, more conversion to bulk water of the structured water molecules is observed, obtaining lower compressibilities.

As mentioned above, the hydrophilic groups of TX114 and Tween 80 are strongly hydrated by water, and it is possible that the $\mathrm{H}_{3} \mathrm{O}^{+}$ions can be associated to the oxyethylene groups $[21,22]$. Strongly hydrated solutes are known as kosmotropes ('structure makers'), while weakly hydrated ones are chaotropes ('structure breakers') [44]. The kosmotropicity of ions can be quantified by hydration entropies, hydration volumes, heat capacity, ion mobility as well as from the viscosity data according to the Jones-Dole equation and $A$ - and $B$-coefficients [45-48]. The coefficient $A$ accounts for the surfactant-surfactant interactions, and $B$ is a measure of structural modifications induced by the surfactant-surfactant/water interactions. In the case of nonelectrolytes, $A=0$. For electrolytic solutions these coefficients can be obtained from the plots of $\left(\eta_{\mathrm{r}}-1\right) C^{-0.5}$ against $C^{0.5}$ where $\eta_{\mathrm{r}}$ is the relative viscosity and $C$ is a molar concentration. A good fit and a linear dependence of the mentioned plots were obtained for TX114 and Tween 80 solutions only for the postmicellar region and $C>10^{-3} \mathrm{M}$ (Figs. 12, 13). The coefficients $A$ and $B$ obtained from these dependences (Fig. 14) are negative and positive, respectively; however, the $A$-coefficients are much smaller in magnitude as compared to $B$-coefficients, 
Fig. 10 A plot of the values of the enthalpy of activation $\left(\Delta H^{*}\right)$ of aqueous solutions of TX114 (curve 1) and Tween 80 (curve 2) at $T=293 \mathrm{~K}$ versus the logarithm of the concentration of surfactant, $C$, as well as the values of $\Delta H^{*}$ of aqueous solutions of TX114 and Tween 80 at $C=10^{-4}, 10^{-3}$ and $10^{-2} \mathrm{M}$ versus the temperature, $T$

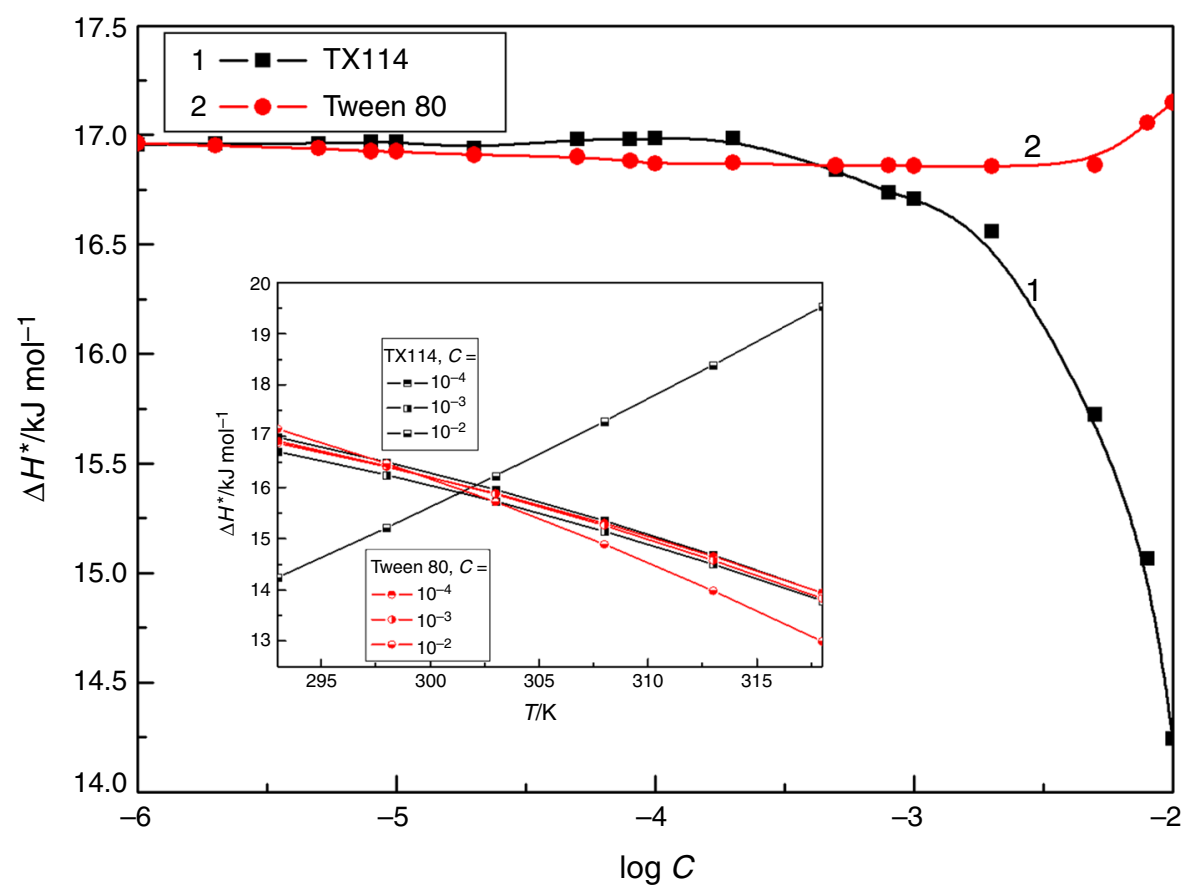

Fig. 11 A plot of the values of the change in heat capacity of activation $\left(\Delta C_{\mathrm{p}}^{*}\right)$ of aqueous solutions of TX114 (curve 1) and Tween 80 (curve 2) at $T=293 \mathrm{~K}$ versus the logarithm of the concentration of surfactant, $C$, as well as the values of $\Delta C_{\mathrm{p}}^{*}$ of aqueous solutions of TX114 and Tween 80 at $C=10^{-4}, 10^{-3}$ and $10^{-2} \mathrm{M}$ versus the temperature, $T$

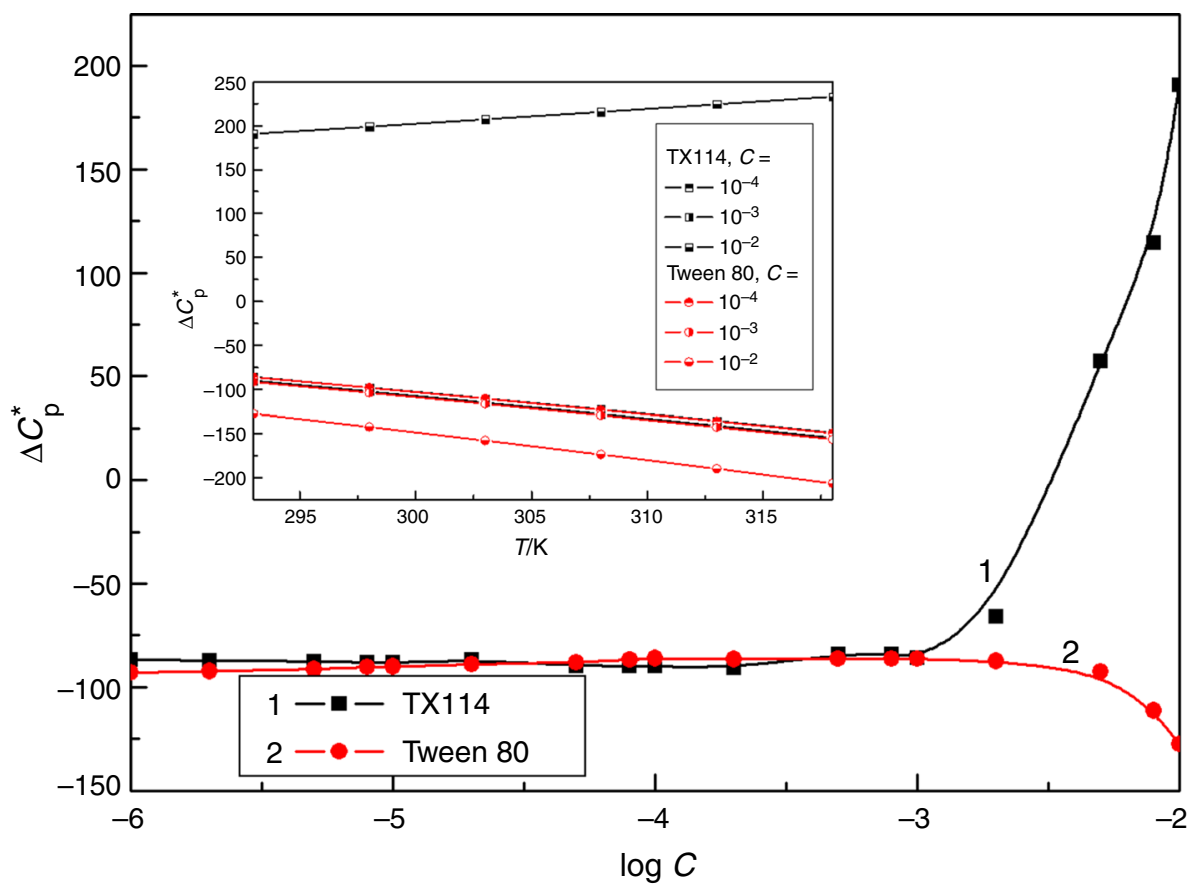

suggesting weak solute-solute and strong solute-solvent interactions in these solutions. It is well known that the $B$ coefficient represents solute-solvent interactions and depends on various factors [34]. In the studied systems, the sign of the $B$-coefficient can be either positive or negative, depending upon the orientation of solvent molecules and structural changes in the solvent around the surfactant molecules/micelles, as well as the solvent's structure-breaking effects. If the decrease in viscosity due to the structure-breaking effect is rather dominant, compared with the increase in viscosity arising from orientation effect of solvent molecules, then the $B$-coefficient will be negative. Negative $B$-coefficient also denotes water structure making, whereas the positive $B$-coefficient denotes a water structure-breaking nature of surfactant molecule. As follows from Fig. 14, with the rising $T$ the 
Fig. 12 A plot of the values of $\left(\eta_{\mathrm{r}}-1\right) C^{-0.5}$ of aqueous solutions of TX114 at $T=293 \mathrm{~K}$ (curve 1), $298 \mathrm{~K}$ (curve 2), $303 \mathrm{~K}$ (curve 3), $308 \mathrm{~K}$ (curve 4), $313 \mathrm{~K}$ (curve 5) and $318 \mathrm{~K}$ (curve 6) versus $C^{0.5}$

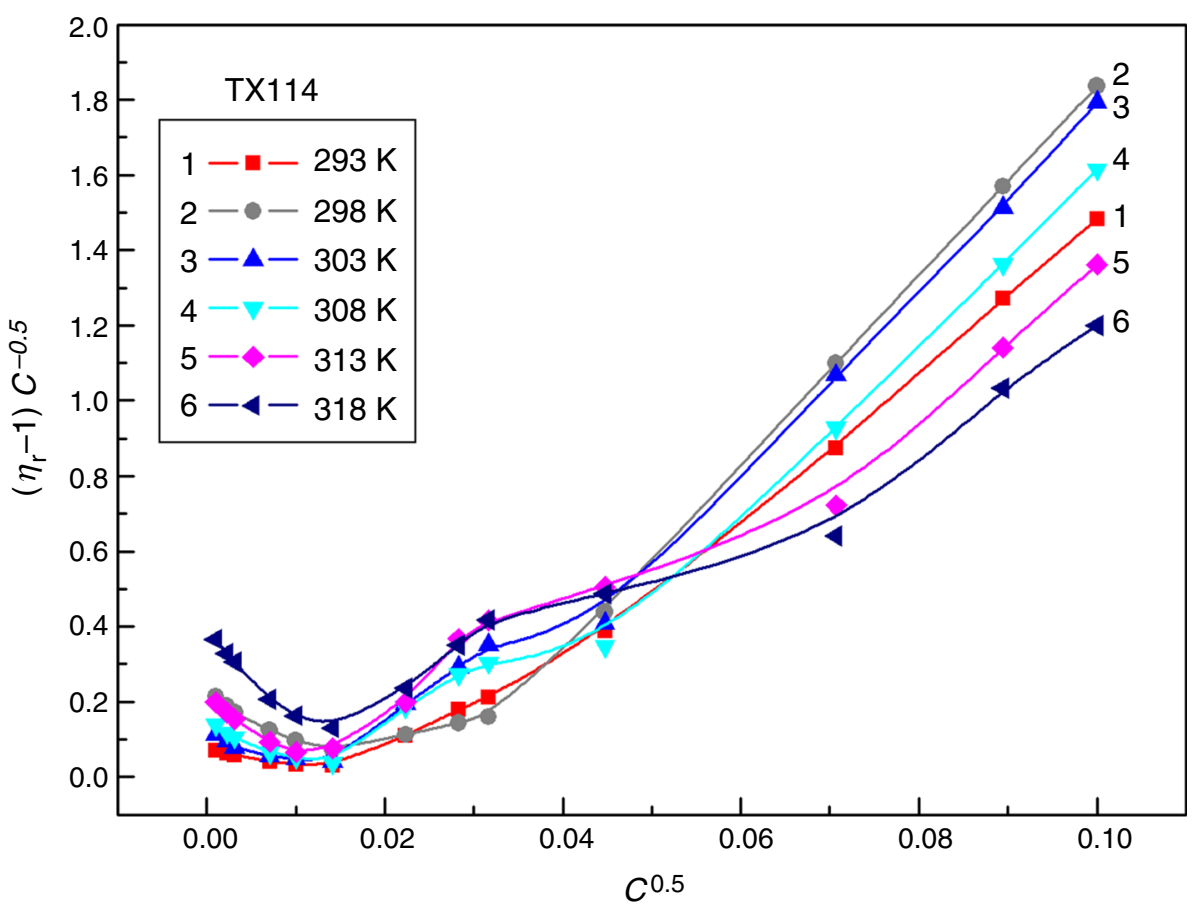

Fig. 13 A plot of the values of $\left(\eta_{\mathrm{r}}-1\right) C^{-0.5}$ of aqueous solutions of Tween 80 at $T=293 \mathrm{~K}$ (curve 1), $298 \mathrm{~K}$ (curve 2), $303 \mathrm{~K}$ (curve 3), $308 \mathrm{~K}$ (curve 4), $313 \mathrm{~K}$ (curve 5) and $318 \mathrm{~K}$ (curve 6 ) versus $C^{0.5}$

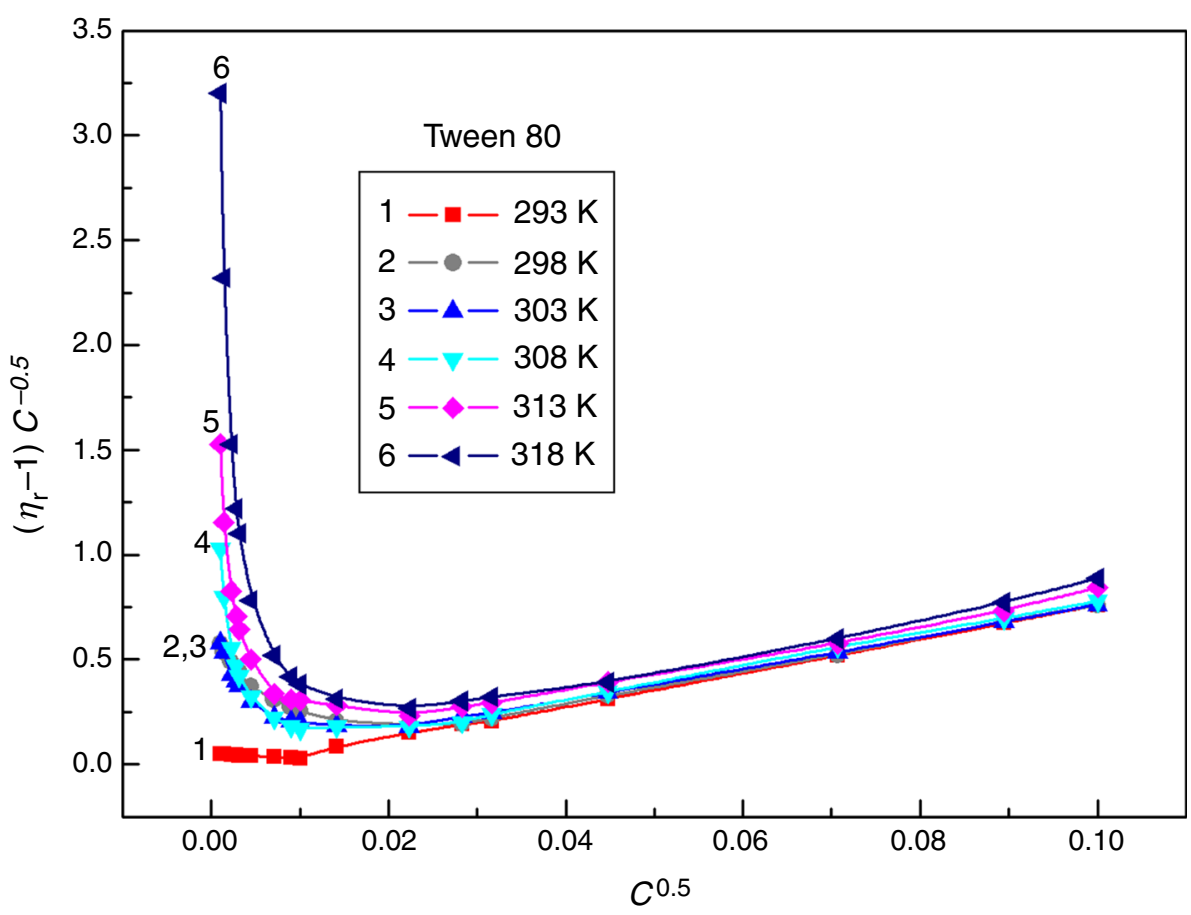

$B$-coefficients remain positive for postmicellar regions, which means that with the addition of surfactant the orientation of solvent molecules becomes predominant, but these values for Tween 80 are smaller than for TX114. On the other hand, these changes in $B$-coefficient with $T$ are different for TX114 and Tween 80. At $T=298 \mathrm{~K}$, the $B$-coefficient for TX114 has the biggest value, while for Tween 80 , the smallest value of $B$ is found at $T=303 \mathrm{~K}$.

Some authors stated that $\mathrm{d} B / \mathrm{d} T$ is a better criterion for determining any solute effect on the structure of solutions depending on temperature. A positive $\mathrm{d} B / \mathrm{d} T$ value in the aqueous surfactant solutions points out that the solute is a structure breaker, whereas a negative $\mathrm{d} B / \mathrm{d} T$ value in the 
Fig. 14 A plot of the values of $A$ (curves $1^{\prime}$ and $2^{\prime}$ ) and $B$ coefficient (curves 1 and 2) of aqueous solutions of TX114 (curves 1 and $1^{\prime}$ ) and Tween 80 (curves 2 and $2^{\prime}$ ) versus the temperature, $T$

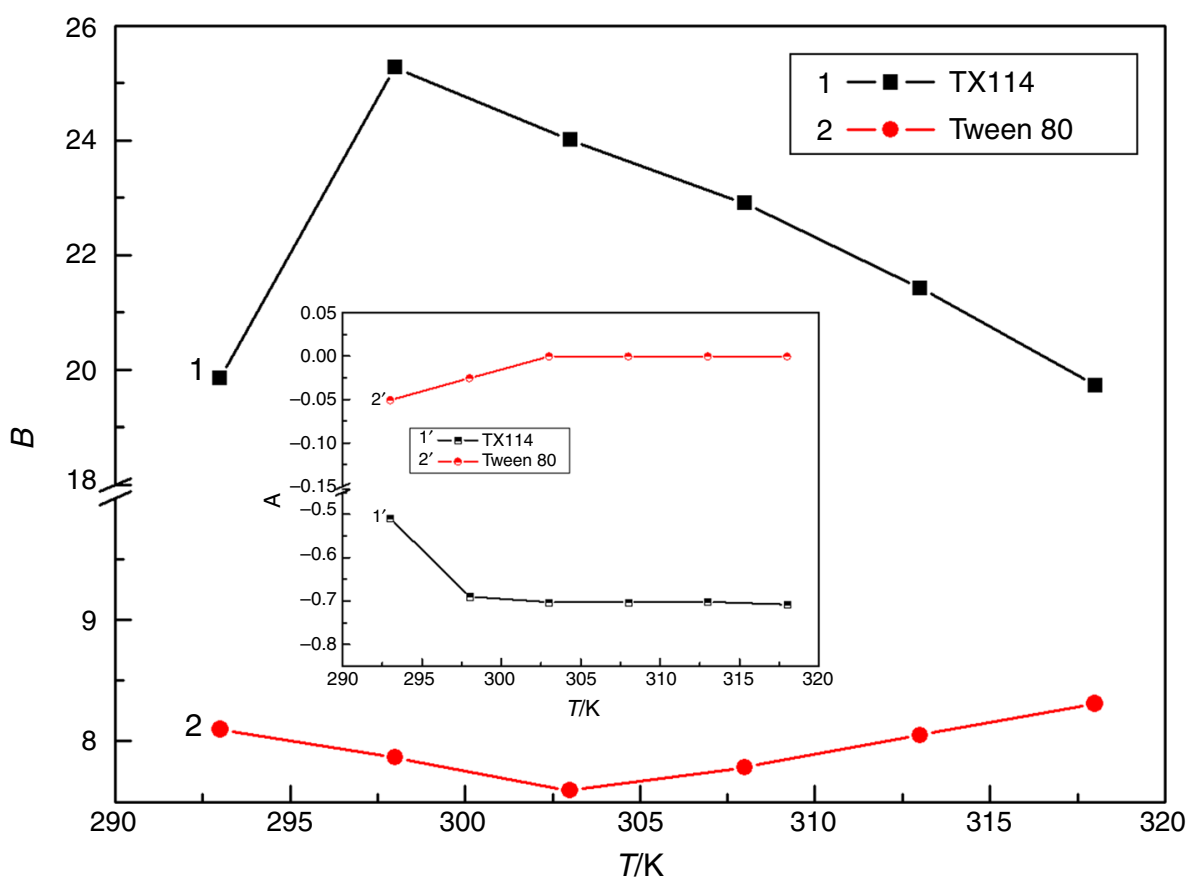

Table 1 Values of the viscosity coefficient $\mathrm{d} B / \mathrm{d} T$ for aqueous solutions of TX114 and Tween 80 at the different temperatures, $T$

\begin{tabular}{lcc}
\hline$T / \mathrm{K}$ & TX114 & Tween 80 \\
\hline 293 & 1.082353 & -0.050347 \\
298 & & \\
303 & -0.355423 & 0.052405 \\
308 & & \\
313 & & \\
318 & & \\
\hline
\end{tabular}

aqueous surfactant solutions indicates that the solute is a structure maker [49]. It results from Table 1 that in the case of TX114 aqueous solutions at $C$ higher than $10^{-3} \mathrm{M}$ the structure-breaking effect becomes significant at temperatures lower than $298 \mathrm{~K}$. In the same range of temperatures, the solutions of Tween 80 behave as structure maker.

\section{Conclusions}

In this paper, some physicochemical properties of aqueous solutions of nonionic surfactants, Triton X-114 (TX114) and Tween 80, are singled out, discussed and compared on the basis of density and viscosity measurements. From the presented data and calculations, it is evident that at a given temperature surfactant-solvent (water) interactions become stronger as increasing surfactant concentration. The values of volume expansivity as well as Sharma parameter and fractional free volume calculated on the basis of density measurements confirm that water molecules are more loosely bound around the Tween 80 molecules than TX114. It is worth emphasizing that viscosity measurements showed that the studied surfactants can behave as a water structure breaker or maker depending on temperature and concentration.

Acknowledgements The financial support from National Science Centre in Poland, Project No. 2014/15/B/ST4/05086, is gratefully acknowledged.

Open Access This article is distributed under the terms of the Creative Commons Attribution 4.0 International License (http://crea tivecommons.org/licenses/by/4.0/), which permits unrestricted use, distribution, and reproduction in any medium, provided you give appropriate credit to the original author(s) and the source, provide a link to the Creative Commons license, and indicate if changes were made.

\section{References}

1. Hinze WL, Pramauro E. A critical review of surfactant mediated phase separations (cloud point extractions): theory and applications. CRC CR Rev Anal Chem. 1993;24:133-77.

2. Heydaria R, Hosseinib M, Zarabi S. A simple method for determination of carmine in food samples based on cloud point extraction and spectrophotometric detection. Spectrochim Acta A. 2015;150:786-91.

3. Vichapong J, Santaladchaiyakit Y, Burakham R, Srijaranai S. Cloud-point extraction and reversed-phase high performance liquid chromatography for analysis of phenolic compounds and their antioxidant activity in Thai local wines. J Food Sci Technol. 2014;51:664-72. 
4. Xie SP, Paau MC, Li CF, Xiao D, Choi MMF. Separation and preconcentration of persistent organic pollutants by cloud point extraction. J Chromatogr A. 2010;1217:2306-17.

5. Hassanien MM, Mortada WI, Kenawy IM. Selective separation of palladium from synthetic highly active liquid waste by cloud point extraction using benzil mono-(2-pyridyl)hydrazone and Triton X-114. J Radioanal Nucl Chem. 2015;303:261-9.

6. Jessen F, Wulff T. Triton X-114 cloud point extraction to subfractionate blood plasma proteins for two-dimensional gel electrophoresis. Anal Biochem. 2015;485:11-7.

7. Alam MS, Siddiq AM, Kamely N, Priyadharshini M, Mythili V, Mandal AB. Influence of the additives on clouding of non-ionic surfactant Triton X-114 solutions: evaluation of thermodynamics at the CP. J Disper Sci Technol. 2015;36:1569-76.

8. Madej K, Sekiewicz A, Kalenik TK, Piekoszewski W. Cloudpoint extraction followed by high pressure liquid chromatography with UV spectrophotometric detection for determination of permethrin in urine samples. Anal Method Instrum. 2015;7:7758-64.

9. Bordier C. Phase separation of integral membrane proteins in Triton X-114 solution. J Biol Chem. 1981;256:1604-7.

10. Dal-Heui L, Eun-Sik K, Ho-Wan Ch. Effect of Tween surfactant components for remediation of toluene-contaminated groundwater. Geosci J. 2005;9:261-7.

11. Tabuchi K, Kawakami S, Shiratori T, Saitoh T. Soil recycling from heavy metal contaminated soil by washing treatment. J Min Mater Process Inst Jpn. 1997;113:1115-20.

12. Azhari H, Strauss M, Hook S, Boyd BJ, Rizwan SB. Stabilising cubosomes with Tween 80 as a step towards targeting lipid nanocarriers to the blood-brain barrier. Eur J Pharm Biopharm. 2016;104:148-55.

13. Rong G, Yang J, Friberg SE. Complex lamellar structure of polyoxyethylene 20 sorbitan oleate and a fatty acid/lecithin lamellar liquid crystal. Langmuir. 1996;12:4286-91.

14. Sannaningannavar FM, Patil SN, Melavanki RM, Navati BS, Ayachit NH. Ultrasonic study of thermo-acoustic parameters of the polysorbate 20,40,60 and 80 liquid surfactants at different temperatures. J Mol Liq. 2014;196:244-8.

15. Zdziennicka A, Szymczyk K, Krawczyk J, Jańczuk B. Critical micelle concentration of some surfactants and thermodynamic parameters of their micellization. Fluid Phase Equilibr. 2012;322-323:126-34.

16. Zhao B, Zhu L, Li W, Chen B. Solubilization and biodegradation of phenanthrene in mixed anionic-nonionic surfactant solutions. Chemosphere. 2005;58:33-40.

17. Penfold J, Thomas RK, Li PX, Petkov JP, Tucker I, Webster JRP, Terry AE. Adsorption at air-water and oil-water interfaces and self-assembly in aqueous solution of ethoxylated polysorbate nonionic surfactants. Langmuir. 2015;31:3003-11.

18. Gautam PK, Gautam RK, Rai R, Pandey JD. Thermodynamic and transport properties of sodium dodecylbenzenesulphonate (SDBS) in aqueous medium over the temperature range $298.15 \mathrm{~K}$ to 333.15 K. J Mol Liq. 2014;191:107-10.

19. Geetha B, Mandala AB. The shape, size, aggregation, hydration, correlation times, and thermodynamic studies on macromonomer micelles. J Chem Phys. 1996;105:9649-56.

20. Posa M. Mixed micelles of binary surfactant mixtures Tween $40-\mathrm{Na}-3,12$-dioxo-5 $\beta$-cholanate and Tween $80-\mathrm{Na}-3,12-$ dioxo-5 $\beta$-cholanate and their thermodynamic description and characterization. Chem Eng Res Des. 2014;92:2826-39.

21. Beyer K. Phase structures, water binding, and molecular dynamics in liquid crystalline and frozen states of the system Triton X-100- $\mathrm{D}_{2} \mathrm{O}$ : a deuteron and carbon NMR study. J Colloid Interface Sci. 1982;86:73-89.

22. El Eini DI, Barry BW, Rhodes J. Micellar size, shape, and hydration of long-chain polyoxyethylene nonionic surfactants. J Colloid Interface Sci. 1976;54:348-51.
23. Desai TR, Dixit SG. Interaction and viscous properties of aqueous solutions of mixed cationic and nonionic surfactants. J Colloid Interface Sci. 1996;177:471-7.

24. Tyrode E, Johnson CM, Kumpulainen A, Rutland MW, Clesson PM. Hydration state of nonionic surfactant monolayers at the liquid/vapor interface: structure determination by vibrational sum frequency spectroscopy. J Am Chem Soc. 2005;127:16848-59.

25. Schick MJ. Nonionic surfactants: physical chemistry, surfactant science series. New York: Marcel Dekker; 1987.

26. Nishikido N. Mixed micelles of polyoxyethylene-type nonionic and anionic surfactants in aqueous solutions. J Colloid Interface Sci. 1977;60:242-51.

27. Robson RJ, Dennis EA. The size, shape, and hydration of nonionic surfactant micelles. Triton X-100. J Phys Chem A. $1977 ; 81: 1075-8$

28. Zhmud B, Tiberg F. Interfacial dynamics and structure of surfactant layers. Adv Colloid Interface Sci. 2005;113:21-42.

29. Liu J, Dong B, Sun D, Wei X, Wang S, Zheng L. Enthalpy measurements for the formation of salt-induced wormlike micelles using isothermal titration microcalorimetry. Colloids Surf A. 2011;380:308-13.

30. Berret JF. Rheology of wormlike micelles: equilibrium properties and shear banding transitions. Molecular gels. Heidelberg: Springer; 2006.

31. Grell E, Lewitzki E, Schneider R, Ilgenfritz G, Grillo I, von Raumer M. Phase transitions in non-ionic detergent micelles. J Therm Anal Calorim. 2002;68:469-78.

32. Sikorska E, Wyrzykowski D, Szutkowski K, Greber K, Lubecka EA, Zhukov I. Thermodynamics, size, and dynamics of zwitterionic dodecylphosphocholine and anionic sodium dodecyl sulfate mixed micelles. J Therm Anal Calorim. 2016;123:511-23.

33. Sambasivam A, Sangwai AV, Sureshkumar R. Self-assembly of nanoparticle-surfactant complexes with rodlike micelles: a molecular dynamics study. Langmuir. 2016;32:1214-9.

34. Gautam PK, Gutam RK, Saroj RS, Pandey JD. Density, viscosity, thermal expansion coefficients and heat capacity ratios of an environmentally hazardous dye Tartrazine in aqueous solutions in the temperature range $293.15 \mathrm{~K}$ to $333.15 \mathrm{~K}$. Proc Natl Acad Sci India A. 2015;85:35-9.

35. Subrahmanyam MSR, Vedanayagam HS, Venkateshwar RD, Rajaiah A, Venkatacharyulu P. Estimation of sharma constant and thermoacoustic properties of fatty acids. J Am Oil Chem Soc. 1995;72:1537-40.

36. Sharma BK. Volume dependence of thermodynamic Grüneisen parameter of fluorocarbon fluids. Phys Lett. 1983;99:227-9.

37. Sharma BK, Reddy RR. Temperature invariance of $S_{0}$-parameter of polymers, Pramana. J Phys. 1987;28:195-203.

38. Sivaram C, Rao JV, Venkatacharyulu P. Cofficient of volume expansion and thermoacoustic parameters in $N$-(phexyloxybenzylidene)-p-tolidine. Cryst Res Technol. 1990;25:939-49.

39. Subba Rao V. Master's Thesis. Nagarjuna University; 1981.

40. Wang YW, Li XX, Zhang ZL, Liu Q, Li D, Wang X. Volumetric, viscosimetric and spectroscopic studies for aqueous solution of ethylene glycol monoethyl ether. J Mol Liq. 2014; 196:192-7.

41. Molina-Bolivar JA, Hierrezuelo JM, Carnero Ruiz C. Selfassembly, hydration, and structures in $N$-decanoyl- $N$-methylglycamide aqueous solutions: effect of salt addition and temperature. J Colloid Interface Sci. 2007;313:656-64.

42. Ferry JD. Viscoelastic properties of polymers. 3rd ed. London: Wiley; 1980.

43. Mukherjee I, Manna K, Dinda G, Ghosh S, Moulik SP. Shear- and temperature-dependent viscosity behavior of two phosphonium-based ionic liquids and surfactant Triton X-100 and their biocidal activities. J Chem Eng Data. 2012;57: 1376-86. 
44. Dhondge SS, Deshmukh DW, Paliwal LJ. Density, speed of sound, viscosity and refractive index properties of aqueous solutions of vitamins $\mathrm{B} 1 . \mathrm{HCl}$ and $\mathrm{B} 6 . \mathrm{HCl}$ at temperatures $(278.15,288.15$, and 298.15) K. J Chem Thermodyn. 2013;58:149-57.

45. Jones G, Dole M. The viscosity of aqueous solutions of strong electrolytes with special reference to barium chloride. J Am Chem Soc. 1929;51:2950-64.

46. Ali A, Hyder S, Akhtar Y. Viscometric studies of $\alpha$-amino acid in aqueous $\mathrm{NaCl}$ and $\mathrm{MgCl}_{2}$ at $303 \mathrm{~K}$. Indian J Phys. 2005;79:157-60.
47. Belibagli K, Ayranci E. Viscosities and apparent molar volumes of some amino acids in water and in $6 \mathrm{M}$ guanidine hydrochloride at $25^{\circ} \mathrm{C}$. J Solution Chem. 1990;19:867-82.

48. Jenkins HDB, Marcus Y. Viscosity B-coefficients of ions in solution. Chem Rev. 1995;95:2695-724.

49. Huque M, Siddiquey IA, Uddin N. Volumetric and viscometric studies on dodecyltrimethylammonium bromide in aqueous and in aqueous amino acid solutions in premicellar region. J Chem Thermodyn. 2006;38:1474-8. 